Jurnal Indonesia Sosial Teknologi: p-ISSN: 2723 - 6609

e-ISSN : 2548-1398

Vol. 1, No. 5 Desember 2020

\title{
PENGARUH TINGKAT SALINITAS BERBEDA TERHADAP PERTUMBUHAN UDANG VANNAMEI (LITOPENAEUS VANNAMEI) YANG DIABLASI
}

\author{
Mutiara Salsabiela \\ Akademi Minyak dan Gas Balongan \\ Email: mutiara.akamigas@gmail.com
}

\begin{abstract}
Salinity is one of the water quality parameters which has an important role in the survival and growth of L. vannamei. Salinity plays a role in the osmoregulation and molting processes in shrimp. In broad salinity (euryhaline), shrimp growth will be disturbed because the osmoregulation process is disturbed. The presence of osmolarity disturbances causes the energy used for growth activities to decrease, thereby reducing the growth rate. Therefore, optimal salinity is needed to support the growth of diablated shrimp. This study aims to examine the effect of different salinity levels on the growth ofvannamei shrimp L. the ablated. This research was conducted for 60 days. This study used an experimental laboratory method with a Systematic Randomized Design (RAS) with 4 treatments and 3 replications for each treatment. Data were analyzed by ANOVA. Meanwhile, the difference in effect between treatments was obtained through the Duncan 3 multiple region test. The results showed that the various levels of salinity of the isoosmotic media at various molting phases had an effect $(\mathrm{p}<0.05)$ on daily growth rates. The best value of daily growth rate (before and after death) was in S3 treatment $(25 \pm 1 \mathrm{ppt}$ ) (close to the final / premolt intermolt isoosmotic) with SGR of $1.17 \%$.
\end{abstract}

Keyword : Salinity, Osmoregulation, Growth, L. Vannamei, Ablation.

\begin{abstract}
Abstrak
Salinitas adalah salah satu parameter kualitas air yang memiliki peranan penting dalam kelulushidupan dan pertumbuhan L. Vannamei. Salinitas berperan dalam proses osmoregulasi dan molting pada udang. Pada salinitas yang luas (euryhaline) pertumbuhan udang akan terganggu dikarenakan proses osmoregulasinya terganggu. Adanya gangguan osmolaritas menyebabkan energi yang digunakan untuk aktivitas pertumbuhan menurun, sehingga menurunkan laju pertumbuhan. Oleh karena itu, dibutuhkan salinitas optimal untuk mendukung pertumbuhan udang yang diablasi. Penelitian ini bertujuan untuk mengkaji pengaruh tingkat salinitas berbeda terhadap pertumbuhan udang vannamei $L$. vannamei yang diablasi. Penelitian ini dilaksanakan selama 60 hari. Penelitian ini menggunakan metode eksperimental laboratories dengan Rancangan Acak Sistematis (RAS) dengan 4 perlakuan dan 3 ulangan pada tiap perlakuannya. Data dianalisis dengan ANOVA. Sementara itu, perbedaan pengaruh antar perlakuan dipeloleh melalui uji wilayah ganda Duncan 3. Hasil penelitian menunjukkan bahwa berbagai tingkat salinitas media isoosmotik pada berbagai fase molting memberikan pengaruh $(\mathrm{p}<0,05)$ terhadap laju pertumbuhan harian. Nilai terbaik laju pertumbuhan harian (sebelum dan setelah mengalami
\end{abstract}


kematian) berada pada perlakuan S3 $(25 \pm 1 \mathrm{ppt})$ (mendekati isoosmotik intermolt akhir/premolt) dengan SGR sebesar 1,17\%.

Kata Kunci : Salinitas, Osmoregulasi, Pertumbuhan, L. Vannamei, Ablasi.

\section{Pendahuluan}

Udang vannamei (Litopenaeus Vannamei) adalah komoditas unggulan sektor perikanan dan kelautan. Menurut Direktorat Jenderal Perikanan Budidaya produksi udang vaname di Indonesia terus mengalami peningkatan dengan kenaikan rata-rata sebesar 20,49\% dari tahun 2010-2014. Dalam menunjang produksi L. Vannamei dibutuhkan salinitas optimal untuk kelulushidupan dan pertumbuhannya.

Salinitas adalah salah satu parameter kualitas air yang memiliki peranan penting dalam kelulushidupan dan pertumbuhan L. Vannamei (Manan \& Putra, 2014). Salinitas berperan dalam proses osmoregulasi dan molting pada udang. Pada salinitas tinggi (hiperosmotik) maupun salinitas rendah (hipoosmotik) pertumbuhan udang akan terganggu dikarenakan proses osmoregulasinya terganggu (Ariyani \& Susanto, n.d.). Osmoregulasi merupakan sistem homeostatis pada udang untuk memelihara kemantapan milieu interior melalui pengaturan keseimbangan konsentrasi osmotik antara intrasel dan ekstrasel. Salinitas sangat berpengaruh terhadap proses osmoregulasi. Apabila salinitas media berada jauh dari kondisi isoosmotik maka proses osmoregulasi akan berlangsung lebih berat sehingga menyerap banyak energi. (Puryono, Anggoro, Suryanti, \& Anwar, 2019). menyatakan apabila energi yang digunakan untuk aktivitas osmoregulasi meningkat maka energi untuk pertumbuhan menurun, sehingga menurunkan laju pertumbuhan.

Berdasarkan hasil penelitian-penelitian berkaitan dengan pengaruh tingkat salinitas terhadap pertumbuhan udang seperti (1) (Salsabiela, 2020) pada pemeliharaan L. vannamei yang diablasi, sebaiknya memperhatikan kebutuhan media isoosmotik yaitu media dengan salinitas 25 $\pm 1-29 \pm 1$ ppt (rentang isoosmotik intermolt akhir/premolt hingga molt). (2) (Syukri \& Ilham, 2016) Menyatakan bahwa salinitas 25 ppt adalah salinitas yang menghasilkan tingkat sintasan dan pertumbuhan post larva udang Windu yang terbaik. (3) (Karim \& Trijuno, 2017) mengatakan salinitas 30 ppt merupakan salinitas optimum untuk menghasilkan pertumbuhan populasi maksimum, TKO minimum dan kandungan nutrisi kopepoda yang tinggi. (4) (Rahman, Rusliadi, \& Putra, 2016) perlakuan dengan salinitas $15 \mathrm{ppt}$ merupakan perlakuan terbaik untuk pertumbuhan dan kelulushidupan udang vannamei. (5) (Maghfiroh, Anggoro, \& Purnomo, 2019) didapatkan nilai osmolaritas media pada tambak intensif udang vaname di Mojo pada salinitas 20 ppt berkisar 616-618 (mOsm/l H2O) dan rata-rata TKO sebesar 37,36 (mOsm/l H2O).

Penelitian-penelitian tersebut mengungkapkan tingkat salinitas optimal terkait pertumbuhan pola osmoregulasi L. vannamei, namun tidak mengungkapkan salinitas yang optimal bagi pertumbuhan $L$. vannamei yang diablasi. Oleh sebab itu, penelitian ini bertujuan untuk mengkaji pengaruh tingkat salinitas berbeda terhadap pertumbuhan udang vannamei L. vannamei yang diablasi. 


\section{Metode Penelitian}

Penelitian ini dilaksanakan selama 60 hari. Penelitian ini dilakukan dengan 2 tahap yaitu penelitian pendahuluan dan penelitian inti. Penelitian pendahuluan ditujukan untuk menetapkan media perlakuan sesuai kebutuhan isoosmotik pada fase molt, postmolt, intermolt awal dan intermolt akhir sebagai landasan manajemen kultivasi L. Vannamei yang diablasi. Selanjutnya, L. Vannamei diaklimatisasi pada media air laut (33 ppt) selama 30 hari untuk pemeriksaan osmolaritas media pada setiap fase molting.

Hasil percobaan pendahuluan tingkat isoosmotik L. Vannamei sesuai fase molting yang selanjutnya akan digunakan sebagai media perlakuan dalam penelitian ini adalah sebagai berikut :

- S1 : 10 ppt (289.20 mOsm/1 $\left.\mathrm{H}_{2} \mathrm{O}\right)$ setara dengan isosmotik fase postmolt ;

- $\mathrm{S} 2$ : 15 ppt (432.80 mOsm/ $\left.\mathrm{H}_{2} \mathrm{O}\right)$ setara dengan isosmotik fase intermolt awal ;

- S3 : 25 1 ppt $\left(725.15 \mathrm{mOsm} / 1 \mathrm{H}_{2} \mathrm{O}\right)$ setara dengan isosmotik fase intermolt akhir ; dan

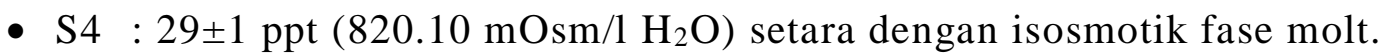

Selanjutnya, penelitian inti dilakukan dengan melakukan pengamatan pertumbuhan dilakukan setiap 10 hari selama selama penelitian. Pengamatan tersebut digunakan untuk membandingkan antar perlakuan.

Metode penelitian yang digunakan adalah metode eksperimental laboratories dengan sistem pengamatan dan perencanaan secara teratur terhadap fenomena yang diteliti. Eksperimen merupakan penyelidikan terencana untuk mendapatkan fakta baru atau memperkuat maupun membantah fakta yang sudah ada sebelumnya. Rancangan percobaan yang digunakan adalah Rancangan Acak Sistematis (RAS) dengan mengaplikasikan 4 perlakuan dan 3 kali pengulangan.

Data pertumbuhan diuji kenormalan dan homogenitas ragam datanya, kemudian sebelum dilakukan pengujian dianalisis lebih lanjut dengan ANOVA. Sementara itu, untuk mengetahui pengaruh perlakuan terhadap pertumbuhan menggunakan uji pembanding ganda yaitu uji Duncan. Keseluruhan data dianalisis menggunakan SPSS 16. Sementara itu, untuk mengetahui nilai optimum dari suatu kurva respon digunakan polinomial orthogonal yang diperoleh dengan menggunakan Microsoft Excel 201

\section{Hasil dan Pembahasan}

Laju pertumbuhan harian atau Spesifik Growth Rate (SGR) L. Vannamei selama penelitian disajikan dalam histogram pada Gambar 1., dimana SGR dianalisis pada saat sebelum dan setelah mengalami kematian. 


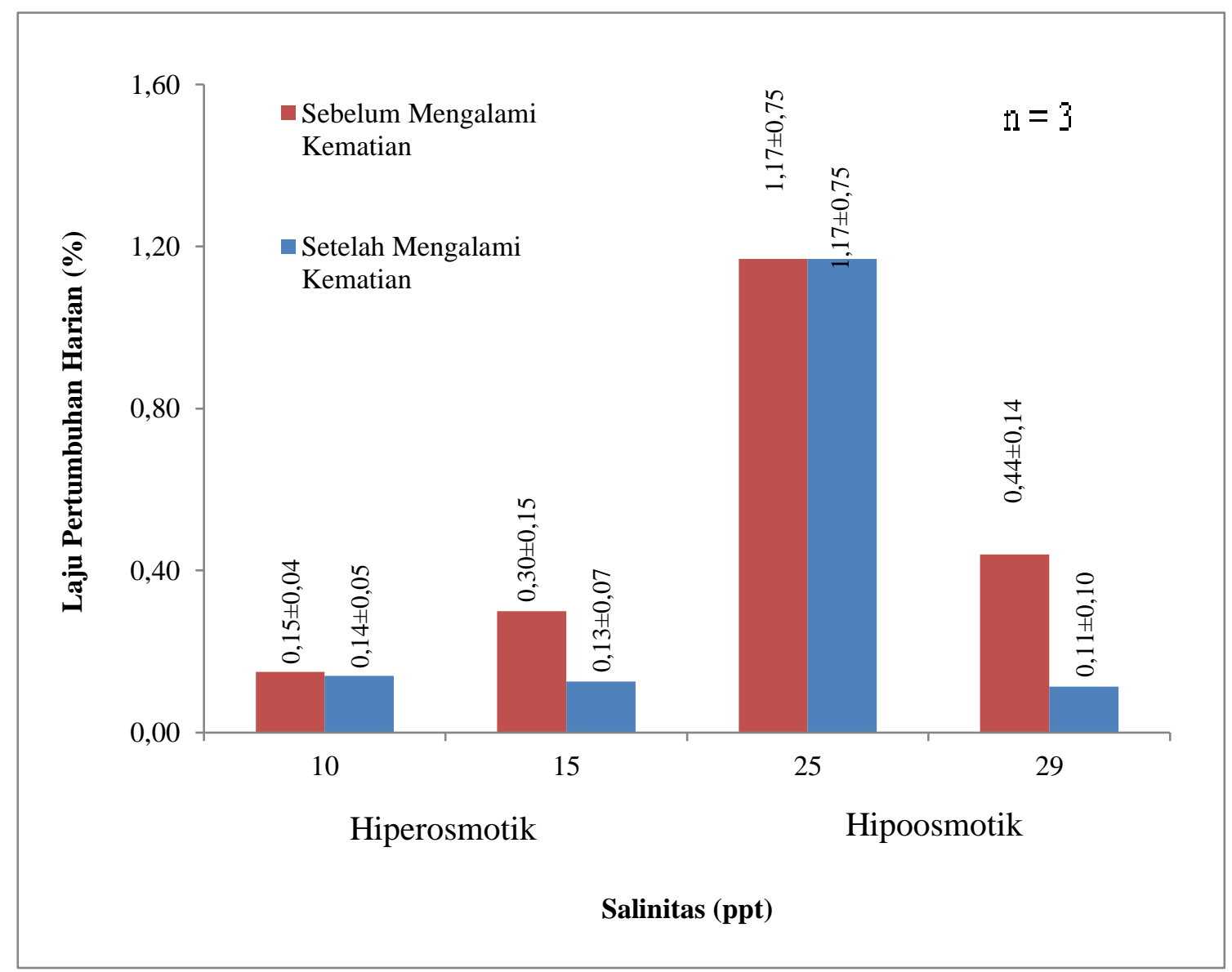

Gambar 1. Histogram Laju Pertumbuhan Harian (\%) L. Vannamei Diablasi dan Dikultivasi pada Berbagai Tingkat Salinitas Sebelum dan Setelah Mengalami Kematian.

Hasil uji normalitas dan homogenitas pada berbagai tingkat salinitas media SGR L. Vannamei sebelum dan setelah mengalami kematian adalah menyebar normal dan homogen $(\mathrm{P}>0,05)$. Hal ini memenuhi syarat untuk dianalisis lebih lanjut dengan ANOVA. Berdasarkan ANOVA SGR dapat diketahui bahwa salinitas berpengaruh terhadap SGR L. Vannamei $\mathrm{P}<0,05)$. Hubungan respon SGR L. Vannamei yang diablasi dan dikultivasi pada berbagai tingkat salinitas media sebelum dan setelah mengalami kematian disajikan pada Gambar 2.

Pada Gambar 2. dapat dilihat bahwa salinitas perlakuan S3 $(25 \pm 1 \mathrm{ppt})$ adalah rentang salinitas terbaik untuk SGR L. Vannamei yang diablasi sebelum dan setelah mengalami kematian, dengan SGR sebesar 1,17\%. Perbedaan antar perlakuan diketahui dengan melakukan uji Duncan, dimana hasil pengujian tersebut disajikan pada Tabel 1. 


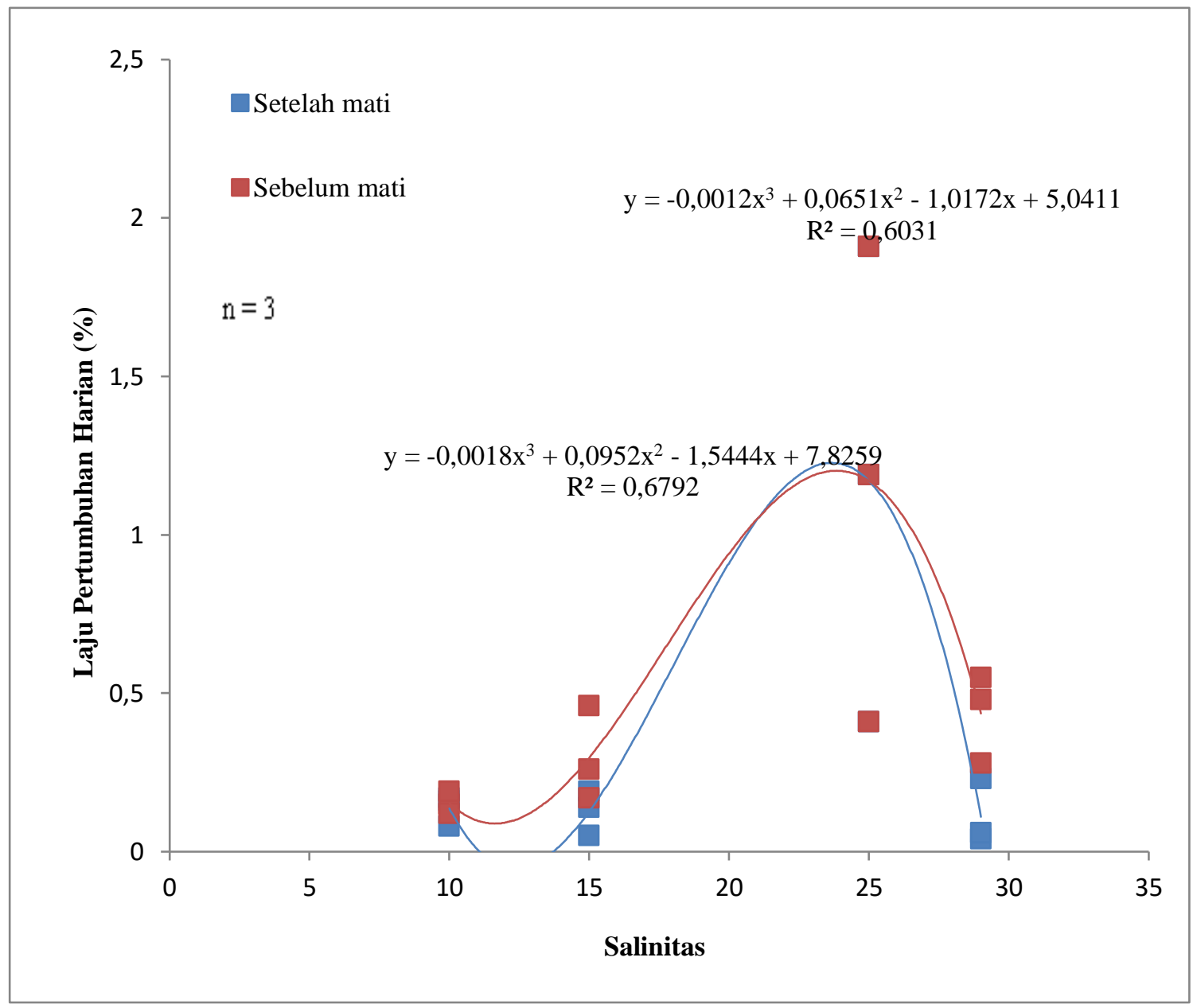

Gambar 2. Kurva Laju Pertumbuhan Harian (\%) L. Vannamei yang Diablasi dan Dikultivasi pada Berbagai Tingkat Salinitas Sebelum dan Setelah Mengalami Kematian

Model respon SGR L. Vannamei pada berbagai tingkat salinitas sebelum dan setelah mengalami kematian adalah sebagai berikut :

$$
\begin{gathered}
\mathrm{Y}=-0.001 \times 3+0,065 \times 2-1,017 \mathrm{x}+5,041(\mathrm{R} 2=0,603) \\
(\text { sebelum mengalami kematian }) \\
\mathrm{Y}=-0.001 \times 3+0,095 \times 2-1,544 \mathrm{x}+7,825(\mathrm{R} 2=0,679) \\
(\text { setelah mengalami kematian })
\end{gathered}
$$

Model persamaan tersebut dapat digunakan untuk memperkirakan respon Y (SGR) apabila X (salinitas) diketahui. Persamaan di atas, mempunyai arti pada R2 = 0,603 yakni hanya 60,3\% faktor salinitas mempengaruhi SGR sebelum L. Vannamei mengalami kematian, sedangkan pada L. Vannamei yang telah mengalami kematian hanya $67,9 \%(\mathrm{R} 2=0,679)$ faktor salinitas mempengaruhi SGR. 
Tabel 1. Uji Duncan Laju Pertumbuhan Harian (\%) L. Vannamei yang Diablasi dan Dikultivasi pada Berbagai Tingkat Salinitas Sebelum dan Sesudah Mengalami Kematian

\begin{tabular}{|c|c|c|c|c|c|c|c|}
\hline & \multirow{2}{*}{$\begin{array}{c}\text { (I) } \\
\text { Salinitas }\end{array}$} & \multirow{2}{*}{$\begin{array}{c}(\mathrm{J}) \\
\text { Salinitas }\end{array}$} & \multirow{2}{*}{$\begin{array}{c}\text { Mean Difference } \\
(\mathrm{I}-\mathrm{J})\end{array}$} & \multirow{2}{*}{$\begin{array}{l}\text { Std. } \\
\text { Error }\end{array}$} & \multirow[b]{2}{*}{ Sig. } & \multicolumn{2}{|c|}{ 95\% Confidence Interval } \\
\hline & & & & & & Lower Bound & Upper Bound \\
\hline \multirow{12}{*}{$\begin{array}{l}\text { Laju } \\
\text { Petumbuhan } \\
\text { Harian } \\
\text { Sebelum } \\
\text { Mengalami } \\
\text { Kematian }\end{array}$} & 10 & 15 & -.14333 & .31773 & .664 & -.8760 & .5893 \\
\hline & & 25 & $-1.01667^{*}$ & .31773 & .013 & -1.7493 & -.2840 \\
\hline & & 29 & -.28333 & .31773 & .399 & -1.0160 & .4493 \\
\hline & 15 & 10 & .14333 & .31773 & .664 & -.5893 & .8760 \\
\hline & & 25 & $-.87333^{*}$ & .31773 & .025 & -1.6060 & -.1407 \\
\hline & & 29 & -.14000 & .31773 & .671 & -.8727 & .5927 \\
\hline & 25 & 10 & $1.01667^{*}$ & .31773 & .013 & .2840 & 1.7493 \\
\hline & & 15 & $.87333^{*}$ & .31773 & .025 & .1407 & 1.6060 \\
\hline & & 29 & $.73333^{*}$ & .31773 & .050 & .0007 & 1.4660 \\
\hline & 29 & 10 & .28333 & .31773 & .399 & -.4493 & 1.0160 \\
\hline & & 15 & .14000 & .31773 & .671 & -.5927 & .8727 \\
\hline & & 25 & $-.73333^{*}$ & .31773 & .050 & -1.4660 & -.0007 \\
\hline \multirow{12}{*}{$\begin{array}{l}\text { Laju } \\
\text { Petumbuhan } \\
\text { Harian } \\
\text { Setelah } \\
\text { Mengalami } \\
\text { Kematian }\end{array}$} & 10 & 15 & .01000 & .31105 & .975 & -.7073 & .7273 \\
\hline & & 25 & $-1.03333^{*}$ & .31105 & .011 & -1.7506 & -.3161 \\
\hline & & 29 & .02333 & .31105 & .942 & -.6939 & .7406 \\
\hline & 15 & 10 & -.01000 & .31105 & .975 & -.7273 & .7073 \\
\hline & & 25 & $-1.04333^{*}$ & .31105 & .010 & -1.7606 & -.3261 \\
\hline & & 29 & .01333 & .31105 & .967 & -.7039 & .7306 \\
\hline & 25 & 10 & $1.03333^{*}$ & .31105 & .011 & .3161 & 1.7506 \\
\hline & & 15 & $1.04333^{*}$ & .31105 & .010 & .3261 & 1.7606 \\
\hline & & 29 & $1.05667^{*}$ & .31105 & .009 & .3394 & 1.7739 \\
\hline & 29 & 10 & -.02333 & .31105 & .942 & -.7406 & .6939 \\
\hline & & 15 & -.01333 & .31105 & .967 & -.7306 & .7039 \\
\hline & & 25 & $-1.05667^{*}$ & .31105 & .009 & -1.7739 & -.3394 \\
\hline
\end{tabular}

* perbedaan rata-rata adalah signifikan pada 0,05

Hasil uji pembanding Duncan sebelum dan setelah L. Vannamei mengalami kematian menunjukkan bahwa terdapat perbedaan pengaruh antara perlakuan S1-S3, S2-S3, S3-S4, sedangkan antara perlakuan S1-S2, S2-S4, S1-S4, tidak terdapat perbedaan pengaruh. Hubungan respon SGR L. Vannamei yang diablasi dan dikultivasi pada berbagai tingkat salinitas media sebelum dan setelah mengalami kematian disajikan pada Gambar 2. 
Hasil pengujian dan perhitungan statistik menunjukkan bahwa akibat salinitas yang berbeda pada media memberikan pengaruh $(\mathrm{P}<0,05)$ terhadap laju pertumbuhan harian atau Spesifik Growth Rate (SGR) L. Vannamei yang diablasi pada setiap perlakuan dan ulangan baik sebelum mengalami kematian maupun setelah mengalami kematian. Menurut (Sahri, Anggoro, \& Suprijanto, 2014) pada salinitas yang luas (euryhaline) dapat menyebabkan kematian massal pada udang disebabkan oleh gangguan keseimbangan osmolaritas. Menurut (Suharyanto, Tjaronge, \& Sulaeman, 2017) dan (Sinyo, Anggoro, \& Soeprobawati, 2019) hal ini dikarenakan semakin tinggi salinitas semakin tinggi pula tekanan osmotic di lingkungan. (Pamungkas, 2012) menjelaskan bahwa tingkat kerja osmotik mempengaruhi fisiologi hewan seperti pertumbuhan, kebiasaan makan, tingkah laku, dan reproduksi. Semakin tinggi Tingkat Kerja Osmotik (TKO) maka laju pertumbuhan biota akan terhambat. Hal ini berkaitan dengan penggunaan energi. Peningkatan penggunaan energi oleh biota air juga mengingkatkan aktivitas osmoregulasi yang diakibatkan oleh tingginya nilai TKO, sehingga jumlah energi yang digunakan untuk pertumbuhan berkurang dan berpotensi menurunkan laju pertumbuhan. (Handayani, Wijianto, Anggoro, \& Informatika, 2018), menambahkan bahwa tinggi rendahnya salinitas media dari media iso-osmotik, berpengaruh terhadap tinggi rendahnya beban kerja osmotik untuk keseimbangan tekanan osmolaritas (media dan darah) maupun keseimbangan kandungan elektrolit (media dan darah), sehingga apabila tingkat kerja osmotik tinggi, maka energi yang terbuang untuk kinerja osmotik lebih besar.

Berdasarkan histogram dan grafik polinomial SGR, rentang salinitas terbaik untuk SGR L. Vannamei yang diablasi sebelum dan setelah mengalami kematian, berada pada perlakuan S3 (25 \pm 1 ppt, setara isoosmotik intermolt akhir) dengan rata-rata 1,17\% (ratarata bobot awal 9,23 g dan rata-rata bobot akhir 10,33 g). Hal ini sesuai dengan penelitian Salsabiela (2020) bahwa pada perlakuan S3 (25 \pm 1 ppt) dengan nilai Tingkat Kerja Osmotik (TKO) sebesar 1,01 $\mathrm{mOsm} / \mathrm{l} \mathrm{H}_{2} \mathrm{O}$ (mendekati isoosmotik intermolt akhir/premolt). Hasil penelitian menunjukkan bahwa pada udang muda yang berumur 1-2 bulan memerlukan kadar garam 15-25 ppt agar pertumbuhan dapat optimal. Menyatakan bahwa pada media 25-26 ppt, dapat meningkatkan laju pertumbuhan tanpa mengubah komposisi asam amino dalam jaringan tubuh udang.

\section{Kesimpulan}

Kesimpulan dari penelitian ini menunjukkan bahwa berbagai tingkat salinitas media isoosmotik pada berbagai fase molting memberikan pengaruh $(\mathrm{p}<0,05)$ terhadap laju pertumbuhan harian. Nilai terbaik laju pertumbuhan harian (sebelum dan setelah mengalami kematian) berada pada perlakuan S3 $(25 \pm 1 \mathrm{ppt})$ (mendekati isoosmotik intermolt akhir/premolt) dengan SGR sebesar 1,17\%. 


\section{Bibliografi}

Ariyani, D., \& Susanto, Sumandi. (n.d.). Iswandi. 2008. Pengaruh Perubahan Salinitas Terhadap Virulensi WSSV Pada Udang Putih Litopenaeus vannamei. Universitas Lampung.

Handayani, V. R., Wijianto, R., Anggoro, A., \& Informatika, M. (2018). Sistem Informasi Pendaftaran Seleksi Kerja Berbasis Web Pada Bkk (Bursa Kerja Khusus) Tunas Insan Karya SMK Negeri 2 Banyumas. Jurnal Evolusi, 6(1), 76-84.

Karim, Muh Yusri, \& Trijuno, Dody Dharmawan. (2017). Respon Tingkat Kerja Osmotik dan Pertumbuhan Populasi Kopepoda Siklopoid Oithona sp. pada Berbagai Salinitas. Jurnal Saintek Peternakan dan Perikanan, 1(2), 54-65.

Maghfiroh, Ana, Anggoro, Sutrisno, \& Purnomo, Pujiono Wahyu. (2019). Pola Osmoregulasi dan Faktor Kondisi Udang Vaname (Litopenaeus Vannamei) yang Dikultivasi di Tambak Intensif Mojo Ulujami Pemalang. Management of Aquatic Resources Journal, 8(3), 177-184.

Manan, Abdul, \& Putra, Fatchurizal Rama. (2014). Monitoring Kualitas Air pada Tambak Pembesaran Udang Vannamei (Litopenaeus vannamei) di Situbondo, Jawa Timur [Monitoring of Water Quality on Rearing Ponds of Vannamei Shrimp (Litopenaeus vannamei) in Situbondo, Jawa Timur]. Jurnal Ilmiah Perikanan Dan Kelautan, 6(2), 137-142.

Pamungkas, Wahyu. (2012). Aktivitas Osmoregulasi, Respons Pertumbuhan, Dan Energetic Cost Pada Ikan Yang Dipelihara Dalam Lingkungan Bersalinitas. Media Akuakultur, 7(1), 44-51.

Puryono, Sri, Anggoro, Sutrisno, Suryanti, Suryanti, \& Anwar, Irwan S. (2019). Pengelolaan Pesisir dan Laut Berbasis Ekosistem. Undip Press.

Rahman, Fadhlur, Rusliadi, Rusliadi, \& Putra, Iskandar. (2016). Growth And Survival Rate Of Western White Prawns (Litopaneaus Vannamei) On Different Salinity. Riau University.

Sahri, Achmad, Anggoro, Sutrisno, \& Suprijanto, Jusup. (2014). Habitat Suitability Modeling of Asian-Moon Scallop (Amusium pleuronectes) in Brebes District Waters, Central Java, Indonesia. International Journal of Marine Science, 4.

Salsabiela, Mutiara. (2020). Pola Osmoregulasi Udang Vannamei (Litopenaeus Vannamei) Dewasa yang Diablasi dan Dikultivasi pada Berbagai Tingkat Salinitas. Gema Wiralodra, 11(1), 143-153.

Sinyo, Yumima, Anggoro, S., \& Soeprobawati, T. R. (2019). Aktivitas Grazing teredo navalis 1 di Habitat Mangrove menggunakan Metode Scan Sampling. SAINTIFIK@, $4(2)$. 
Pengaruh Tingkat Salinitas Berbeda terhadap Pertumbuhan Udang Vannamei

(Litopenaeus Vannamei) yang Diablasi

Suharyanto, Suharyanto, Tjaronge, Muhammad, \& Sulaeman, Sulaeman. (2017). Pengaruh Dosis Glisin yang Berbeda terhadap Tingkat Kanibalisme, Sintasan, dan Pertumbuhan Kepiting Bakau (Scylla Serrata. Prosiding Forum Inovasi Teknologi Akuakultur, 145-152.

Syukri, Muhammad, \& Ilham, Muhammad. (2016). Pengaruh salinitas terhadap sintasan dan pertumbuhan larva udang windu (Penaeus monodon). Jurnal Galung Tropika, 5(2), 86-96. 